\title{
Use of board games in higher education literature review
}

Edward Smith, Sheffield Hallam University, Sheffield, UK. Email: b4010674@my.shu.ac.uk Lewis Golding, Sheffield Hallam University, Sheffield, UK, Email: b5020351@my.shu.ac.uk

\begin{abstract}
There is a long standing history of mathematical games and puzzles being used to support mathematical thinking and concepts. The Maths Arcade is a recent initiative designed to provide an environment for students to play games in order to communicate with fellow students whilst developing a range of skills. The purpose of this study was to determine how these skills are developed and how they link to different games, we have found the evidence for this through reviewing a variety of sources focussing on game-play. We found that the playing of board games is fundamentally linked to the development of mathematical thinking and skills. These are developed in many ways including trial and improvement and discussion.
\end{abstract}

Keywords: games, mathematical thinking, strategic thinking, problem solving, university.

\section{Introduction}

The Maths Arcade was designed as a drop in session for universities, to provide a safe space for students to get to know other students and lecturers, whilst also providing them with the opportunity to develop strategic thinking and problem solving skills. Students had the chance to play various strategic and challenging board games, designed to develop these skills (Bradshaw, 2011). For more information on the Maths Arcade see Bradshaw and Rowlett (2012). This review was carried out in order to argue the connection that the playing of strategic board games helps to develop these skills. Using our findings there is great potential to further develop the Maths Arcade to include games created solely for enhancing these skills.

Two or more player strategy games can be traced back to before $2000 \mathrm{BC}$, and are still being created today (Averbach \& Chein, 2000). Whilst most games are created to be a fun past time, there are an increasing number of board games which include mathematical skills. It is hard to distinguish between games which involve a mathematical way of thinking and those which don't, however it is clear that some games are more mathematical than others (Silva, 2011). For the Maths Arcade games were chosen which display these mathematical qualities in order to improve the strategic thinking and problem solving skills of students. This article will discuss the need for these skills, and the evidence linking the playing of board games to the development of these skills.

\section{Methodology}

Relevant papers on games and their use in higher education to develop mathematical/logical thinking were found through searches in the Sheffield Hallam University library gateway and Google Scholar. In an attempt to ensure that relevant studies weren't missed, the keywords "games or puzzles or board games or strategy games" and "logical thinking or strategic thinking or mathematical thinking or problem solving", and "higher education or tertiary education or university" were used.

Additionally, as each paper was reviewed, the references it cited were studied and papers which cite it, found using Google Scholar, were reviewed. 
In total 20 relevant papers were identified and these were all read and reviewed. It was found that some of these also were not relevant due to focussing on game theory, which is not the topic of interest here, and these were rejected. Papers that were rejected were looking at online or video games rather than physical games. Papers focused at school level were included only if they focused specifically on problem-solving or strategic thinking.

As papers were reviewed, common themes became apparent, and quotes showing evidence for these skills being developed through the playing of games were recorded against these themes as appropriate. The remainder of this paper shares these themes.

\section{History of games being used to educate/develop skills}

The use of games for educational purposes can be traced to the use of war games in the 1600s, where, according to Gredler (2004), their purpose was to improve the strategic planning of armies and naval forces. Gredler recognises how games are used less, as students move up through education, quoting a remark by Rieber that "although educational games are accepted in elementary school, teacher and parent interest in their use declines in the later grades". This can be observed in higher education at degree level, where the style of learning is often replaced by more traditional lectures. Whilst it may be the case that, as more complex topics are studied, it becomes more difficult to incorporate this into games, there is no evidence to suggest that they can't still be used as a method in order to develop other skills and techniques.

\section{Why mathematical/strategic thinking is important}

It is widely recognised that the teaching in UK schools often focuses on students' ability to compute mathematical solutions in an exam style situation (Ofsted, 2012) rather than on their ability to understand and apply the mathematics being taught. This can lead to a reduced emphasis on strategic and mathematical thinking. Stein, et al. (1996) summarise this by saying "increased emphasis is being placed not only on students' capacity to understand the substance of mathematics but also on their capacity to "do mathematics". This has an effect when students reach higher levels of study as these skills are not as developed as much as is necessary for the advanced topics studied in higher education. This was recognised by Burton (1984) who says "few pupils leave the school system with mathematical success as measured by examinations, and those who do consistently surprise their university tutors by their lack of facility in thinking mathematically". Students need to develop these skills when they reach a higher level of study as they are required for further study and graduate-level employment. The Maths Arcade provides the opportunity for students to do this whilst in a fun and enjoyable environment. An article by Forsyth (2012) discusses a news report in 2012 about the then Norwegian minister for international development, Heikki Holmas who is a regular and experienced player of board games. This highlights how the playing of board games has helped him to develop the strategic thinking skills required in his job. This is further evidence suggesting that the playing of board games is a valuable exercise, developing the skills needed for employment - many job interviews in fact ask for evidence of good problem solving skills.

\section{How strategic thinking is developed}

The use of game-play allows participants to develop a strategy for success over the long term through the outcomes of the previous games played. Creation of a winning pattern can often include subconscious aspects. There are various generic factors involved when developing a winning strategy during game-play. Games that do not share many common similarities often affect separate strategy making skills, depending on the level of skill involved. The use of trial and improvement is key to strategy development and tabulating results and routes taken is effective to analyse and improve the quality of game-play. Oldfield (1991b) notes that "the value of some form of record keeping is quickly apparent, and pupils are encouraged to develop a system". Trial and improvement 
skills are directly coupled with proving skills, justifying the level of success of previous actions. The player becomes more aware of which decisions lead to the highest probability of success as experience and comprehension of the game increase. Reasoning is one skill that can be developed through game-play, where one devises a system to consider all viable options available at the current time in order to gain the most benefit out of their turn. This is largely considered a background process that is not often verbally discussed without prompting. Klein and Freitag (1991) studied the effects of using an instructional game on motivation and performance, they found that whilst using instructional games as a method of delivering practice enhanced the motivation of students' it did not contribute to their enhanced performance when compared with traditional methods of practise. This shows that motivation alone is not strong enough to significantly enhance the performance of a student, but greater results may be achieved by combining the effect of instructional gameplay with the enhancement of other skills such as communication skills.

\section{How game-play enables communication skills}

Discussion of mathematical ideas enables the thought processes involved to be expressed, analysed and assessed. Stimulating such discussion through the means of game-play allows us to construct comparisons for how different games influence different aspects of mathematical thinking. Oldfield (1991a) states that in traditional classroom settings "pupils were struggling to express what they were doing", which shows us that there is a need for a different approach in the way pupils are taught to express mathematical thoughts and ideas. Mathematical understanding can be developed through the discussions between students whilst playing the games (Bragg, 2003) indicating that the playing of games is an effective alternative to the normal teaching methods. It could be argued therefore that the use of games should be implemented in a learning environment, in order to encourage outward communication of mathematical thoughts and to develop discussion skills.

The type of game can offer alternative forms of discussion and therefore potentially different mathematical thinking mechanisms. Working as a group allows communication throughout the course of the game between participants whereas working alone against other individuals will more commonly stimulate discussion after the game is complete (Oldfield 1991a). The mathematical thinking and discussion involved during the game is different to that involved retrospectively. This is because the discussion after gameplay will be influenced by what could have been done differently, rather than the discussion during a game focussed on what should be done presently. If two groups are working on the same problem, this could stimulate discussion in a more competitive sense. This was noted by Herbert and Pierce (2004) who comment that "competition was an important factor in the success of the program. Students formulated ever more complex strategies as they strived to win games".

\section{Mathematical thinking in an academic environment}

Students in an academic setting who have become accustomed to the typical teaching methods of a learning environment are an excellent set of participants for studying their mathematical thinking, especially so for those that already have a great baseline knowledge of mathematics. Herbert and Pierce studied the effect of game-play amongst a select set of gifted lower secondary school students in a controlled environment. They noted that gifted students are not necessarily highly motivated and so still require positive reinforcement and engagement in order for a long-term gain of skill development to be made. When students were tasked with creating their own games, it was shown that prior game-play experience was vital in applying new concepts. It was noted that allowing the students to create their own games enabled them to demonstrate their ability to use the ideas found in other games to develop an original, functioning game (Herbert \& Pierce, 2004). This serves 
as direct evidence that experience is correlated to the learning of concept and strategy. Herbert and Pierce found like Oldfield that game-play includes heavy incorporation of an "if-then analysis" of many possible alternative moves showing that repetition of this analysis will solidify such skill (Oldfield 1991b). Fitting with our ideas that game-play enhances mathematical concepts Herbert and Pierce note that strategy games have the potential to extend students' higher order thinking.

\section{Games being used for younger age groups}

There is evidence to suggest that using games enables students to develop problem solving and a deeper understanding of concepts. Ernest (1986) discusses a teaching experiment by Biggs in 1985 which involved the use of games in the education of 7-13 year olds. "Dr Biggs observed not only that these children's conceptual understanding deepened, but that their problem solving abilities grew." It should be noted that the games included in this experiment by Biggs may not be of the same style as the games included in university Maths Arcades, but there is no evidence to suggest that these findings would not be the same for different types of games. Ernest concludes his article by suggesting that games should be included in the mathematics curriculum and that they "have a vital part to play in aiding pupils' achievement and success in mathematics." Whilst games are clearly influential and effective in the education of younger children, the evidence relating this to higher levels of education is limited. The Maths Arcade can be viewed as a tool to use this evidence from lower education and apply this in a higher education context in order to develop these skills further. Ernest (1986) also discusses the work of two Americans, Bright and Kraus, who discovered that the playing of mathematical games can stimulate problem solving skills which can in turn help to develop them through the development of strategy as the games are played. In the study, it is found that this is the case for both experienced and inexperienced problem solvers.

\section{Choice of games}

The games chosen as part of the Maths Arcade are games which have little to no element of chance or luck. The benefit of this is that to be successful, "players must develop better strategies than their opponents" (Herbert \& Pierce, 2004). The competiveness amongst peers playing the games leads to discussions and development of strategy as the games are played more and more over time. When observing students playing board games in the library, Alvarez notes that students leave the table each week strategizing more successful outcomes and "looking forward to the next challenge" (Alvarez, 2017). The games used as part of the Maths Arcade challenge the students across a wide range of skills, enabling all of these to be developed. In fact Alvarez notes that critical thinking, problem solving, oral and written communication and analysing information can all be developed during the playing of games. Some, if not all of these, are essential to students whilst still in education and when in employment after education.

\section{Conclusion}

We have confirmed through the analysis of the works found, that the playing of board games enhances skills and attributes needed in the study of mathematics. The Maths Arcade houses a variety of games needed to develop these skills. These include problem solving skills, trial and improvement, strategic thinking and mathematical discussion. We have found that game-play allows these skills to develop and improve. There is an abundance of evidence to show that playing games at a young age can help with learning and understanding but this is seldom at a higher level of education. Strategic thinking and problem solving are essential to accessing higher levels of employment but often at higher education these skills are found to be lacking. The Maths Arcade is intended to provide an ideal opportunity for development of mathematical thinking in an enjoyable environment. 


\section{Acknowledgements}

The work of the authors as undergraduate student researchers was funded by Sheffield Hallam University through a Teaching Enhancement Grant. The work was supervised by Peter Rowlett and Claire Cornock.

\section{References}

Alvarez, V., 2017. Engaging Students in the Library Through Tabletop Gaming. Knowledge Quest, 45(4), pp. 40-48.

Averbach, B. \& Chein, O., 2000. Games of Strategy for Two Players. In: Problem Solving through Recreational Mathematics. Mineola, New York: Dover Publications, Inc, p. 213.

Bradshaw, N., 2011. The University of Greenwich Maths Arcade. MSOR Connections, 11(3), pp. 2629.

Bradshaw, N. \& Rowlett, P. eds., 2012. Maths Arcade: stretching and supporting mathematical thinking. Birmingham: Maths, Stats \& OR Network.

Bragg, L., 2003. Children's perspectives on mathematics and game playing. Geelong, Victoria, MERGA Inc. , pp. 160-167.

Burton, L., 1984. Mathematical Thinking: The Struggle for Meaning. Journal for Research in Mathematics Education, 15(1), pp. 35-49

Ernest, P., 1986. Games. A Rationale for Their Use in the Teaching of Mathematics in School. Mathematics in School, 15(1), pp. 2-5.

Forsyth, E., 2012. Learning Through Play: Games and Crowdsourcing for Adult Education. APLIS, 25(4), pp. 166-173.

Gredler, M. E., 2004. Games and Simulations and Their Relationships to Learning. In: Handbook of research on educational communications and technology 2. Mahwah $\mathrm{NJ}$ : Lawrence Erlbaum Associates Publishers, pp. 571-581.

Herbert, S. \& Pierce, R., 2004. Gifted and lifted higher: And exploration of the development of higher order thinking skills of gifted students played strategy games. TalentEd, 22(1).

Klein, J. D. \& Freitag, E., 1991. Effects on Using an Instructional Game on Motivation and Performance. Journal of Educational Research, 84(5), pp. 303-309.

Ofsted, 2012. Mathematics: made to measure. Messages from inspection evidence (Report No. 110159). Manchester: Office for Standards in Education, Children's Services and Skills.

Oldfield, B. J., 1991a. Games in the Learning of Mathematics Part 2: Games to Stimulate Mathematical Discussion. Mathematics in School , 20(2), pp. 7-9.

Oldfield, B. J., 1991b. Games in the Learning of Mathematics Part 3: Games for Developing Strategies. Mathematics in School , 20(3), pp. 16-18. 
Silva, J. N., 2011. On Mathematical Games. Journal of the British Society for the History of Mathematics, 26(2), pp. 81-104.

Stein, M. K., Grover, B. W. \& Henningsen, M., 1996. Building Student Capacity for Mathematical Thinking and Reasoning: An Analysis of Mathematical Tasks use in Reform Classrooms. American Educational Research Journal, 33(2), pp. 455-488. 